\title{
BMJ Open Surveys of parents and clinicians concerning the minimally important difference of probiotic therapy for prevention of paediatric antibiotic- associated diarrhoea
}

\author{
Samaneh Khanpour Ardestani, ${ }^{1}$ Joan L Robinson, ${ }^{1}$ Levinus A Dieleman, ${ }^{2}$ \\ Hien Q Huynh, ${ }^{1}$ Hsing Jou, ${ }^{1}$ Sunita Vohra ${ }^{1,2}$
}

To cite: Khanpour Ardestani S, Robinson JL, Dieleman LA, et al. Surveys of parents and clinicians concerning the minimally important difference of probiotic therapy for prevention of paediatric antibiotic-associated diarrhoea. BMJ Open 2019;9:e024651. doi:10.1136/ bmjopen-2018-024651

- Prepublication history and additional material for this paper are available online. To view these files, please visit the journal online (http://dx.doi org/10.1136/bmjopen-2018024651).

Received 6 June 2018 Revised 6 November 2018 Accepted 21 January 2019

A) Check for updates

(c) Author(s) (or their employer(s)) 2019. Re-use permitted under CC BY-NC. No commercial re-use. See rights and permissions. Published by BMJ.

${ }^{1}$ Department of Pediatrics, Faculty of Medicine and Dentistry, University of Alberta, Edmonton, Alberta, Canada ${ }^{2}$ Department of Medicine, Faculty of Medicine and Dentistry, University of Alberta, Edmonton, Alberta, Canada

Correspondence to Dr Sunita Vohra; svohra@ualberta.ca

\section{ABSTRACT}

Objectives To establish the minimally important difference (MID) that would prompt parents and clinicians to use probiotics for prevention of paediatric antibioticassociated diarrhoea (AAD) and to obtain parent and clinician opinion about the most important outcomes in clinical trials of AAD.

Methods In this survey, parents of children presenting to the emergency department of a Canadian tertiary care children's hospital and paediatricians working in that hospital were approached. A range of potential MIDs were presented and participants selected one that they would require to use probiotics for $A A D$ prevention. In addition, participants were asked to rate a list of outcomes they would consider to be important in clinical trials of AAD. Results In total, 127 parents and 45 paediatricians participated. About 51\% (64/125) of parents and 51\% (21/41) of clinicians responding to the MID question reported they would use probiotics if it reduced the risk of AAD by $39 \%$ (ie, reduce the risk of AAD from $19 \%$ to $12 \%$ ). The most important outcomes to parents, in descending order, were need for hospitalisation, prevention of dehydration, disruption of normal daily activities, diarrhoea duration and physician revisit. Paediatricians considered need for hospitalisation along with physician revisit as the most important outcomes. They rated prevention of dehydration, diarrhoea duration and stool frequency as important outcomes as well.

Conclusion There is good agreement between parents and clinicians regarding how effective probiotics would need to be in preventing AAD in order to warrant use. This information, along with outcomes perceived to be most important, will help in the design of future clinical trials.

\section{BACKGROUND}

Probiotics are defined as 'live microorganisms which, when administered in adequate amounts, confer a health benefit on the host'. ${ }^{2}$ Research shows a substantial increase in probiotic use in clinical and research settings and among the general public in the last three decades.
Strengths and limitations of this study

- This is the first study to seek parent and clinician opinions about minimally important difference of probiotic therapy for preventing paediatric antibiotic-associated diarrhoea.

- Face validity and comprehensibility of the survey were tested.

- Response rate of parents/guardians was very high. However, response rate of clinicians was low.

- Restricting our participants to English-speaking population and parents of children presenting to a children's hospital emergency department might affect the generalisability of our findings.

According to a 2015 Cochrane systematic review, ${ }^{4}$ probiotics may be effective for prevention of antibiotic-associated diarrhoea (AAD) in children (pooled relative risk $(\mathrm{RR})=0.46$, $95 \%$ CI 0.35 to 0.61 ), AAD can be delayed up to 8 weeks after initiation of antibiotics. ${ }^{5}$ Its incidence varies considerably $(5 \%-62 \%)$ depending on the patient population, setting, type and duration of antibiotics. ${ }^{6-12}$ Although mild-to-moderate diarrhoea is more common, serious complications such as dehydration and Clostridium difficile infection can result. ${ }^{11} 12$ The proposed mechanism for the development of AAD is that antibiotics influence the gut microbial balance, altering its protective functions and leading to diarrhoea. ${ }^{13} \mathrm{AAD}$ is particularly important in children as antibiotics are frequently prescribed in this population ${ }^{14}$ and they are more likely to develop dehydration from diarrhoea than are adults.

As the gold standard for determining treatment efficacy, ${ }^{15}$ randomised clinical trials (RCTs) are powered to detect the difference or change in the outcome of interest between 
study groups. ${ }^{16}$ However, this difference or change must outweigh the risks, costs and inconvenience of the intervention in order to warrant implementation. The smallest difference or change that meets these criteria is called the minimally important difference (MID).${ }^{17}{ }^{18}$ MID also informs the sample size calculation of RCTs. ${ }^{17}$

Historically, MID was determined by healthcare providers; more recently, patient or parent input on MID is being sought. ${ }^{18} 19$ Recent calls to establish patient-determined MID are especially relevant for therapies that are accessed by consumers without a prescription (eg, probiotics).

To date, more than $20 \mathrm{RCTs}^{20-39}$ have studied the effectiveness and safety of probiotics for prevention of AAD in children. None of these studies reported seeking the perspective of children or parents about the most relevant outcomes and associated MID.

Different methods, including surveys, Delphi methods and interviews, can be used to elicit opinions about the change or difference in an outcome that is perceived to be important. ${ }^{1640}$ Accordingly, we conducted a survey to establish the MID in diarrhoea incidence that would lead parents/guardians to use probiotic therapy for prevention of $\mathrm{AAD}$ in their children.

As our secondary objective, we also obtained the opinions of clinicians and compared them with the opinions of parents/guardians. Factors associated with the size of MID (demographics, previous familiarity and experience with probiotics and AAD) in each group were explored. Furthermore, parents/guardians and clinicians rated the importance of outcomes that should be measured in AAD trials, other than the risk of AAD.

\section{METHODS}

\section{Sampling frame and administration}

\section{Parents/guardians}

We approached parents/guardians of children in the waiting room of the emergency department at the Stollery Children's Hospital, a large urban tertiary care hospital in Edmonton, Canada. They were eligible if their children were less than 17 years old and had taken antibiotics at least one time in their lives. Exclusion criteria were inability to communicate in English or previous participation in the study. Participants were provided a paper-based survey (online supplementary appendix A) by a study team member (SKA) who obtained consent for participation and provided help to understand the questions as required.

\section{Clinicians}

We approached a convenience sample of general paediatricians and all sub-specialists from gastroenterology, infectious diseases and emergency medicine in active practice at the Stollery Children's Hospital. Clinicians were given electronic surveys (online supplementary appendix B) using REDCap; ${ }^{41}$; paper surveys were provided to those who did not respond to the electronic surveys.

\section{Development of survey}

Validated surveys were developed based on the literature, discussion with experts, and consultation with parents and paediatricians. Clinical sensibility and pilot testing were performed on a group of parents $(n=5)$ and clinicians $(n=5)$ with diverse demographic characteristics to ensure face validity, comprehensiveness, clarity, acceptability and ease of administration of the surveys. The surveys (online supplementary appendices A and B) consisted of two sections: in the first section, we asked participants for their opinions and behaviour about probiotics. In the second section, we introduced a trade-off tool consisting of potential advantages and disadvantages of probiotic therapy. ${ }^{42}{ }^{42}$ For parents/ guardians, this was complemented by presentation of a scenario wherein the risk of developing AAD in children was shown to be $19 \%$ as stated in a 2015 systematic review. ${ }^{4}$ Then, a range of higher and lower MIDs were presented. These options were calculated based on the pooled RR of probiotics to reduce the incidence of paediatric $\mathrm{AAD}$ and the corresponding lower and upper limits of $95 \%$ confidence interval (pooled $\mathrm{RR}=0.46,95 \%$ CI 0.35 to 0.61 ). We asked participants to select the MID that was closest to what they would require in order to use probiotics for AAD prevention. The rationale of presenting limited response options was to obtain the opinions of parents and clinicians for the range of treatment effect that was realistic and in keeping with the published literature. A research team member was available to respond to any questions that parents/guardians might have had and to make sure that they had a good understanding of the concept of the question. For parents/guardians, risks were expressed as frequencies per 100 patients to facilitate ease of understanding. ${ }^{43}$ Positive and negative wording with corresponding visual illustration (ie, happy and sad faces) were used to promote clarity. ${ }^{44}$ Format and questions of clinician survey were mainly adapted from the survey study carried out by Li et al. ${ }^{45}$

Finally, we asked participants to score a list of outcomes they would consider important to be measured in clinical trials of AAD. We used the nine-point scale suggested by the Grading of Recommendations Assessment, Development and Evaluation (GRADE) group to score the importance of outcomes. ${ }^{46}$ In this scale, scores of $1-3$ represents outcomes of limited importance, 4-6 important but not critical and 7-9 indicates outcomes that are of critical importance.

\section{Sample size justification}

A sample size of 122 parents/guardians and 44 clinicians would achieve $80 \%$ power to detect an effect size of 0.3 (medium effect) and 0.5 (large effect), respectively, using a $3 \mathrm{df} \mathrm{X}^{2}$ test with a significance level (alpha) of 0.05 , two-sided. ${ }^{47}$ According to Cohen et al, ${ }^{47}$ effect size is the measure of the magnitude of the $\mathrm{X}^{2}$ that is to be detected. 


\section{Statistical analysis}

Frequencies of MID estimates of parents/guardians and clinicians were reported as n (\%). MID estimates derived from clinicians and parents/guardians were compared using $\mathrm{X}^{2}$ test. Participant opinions and behaviours were reported as frequencies for each question. A multinomial logistic regression model was conducted to determine factors associated with the size of MID in clinicians and parents/guardians. $\mathrm{P}$ value $<0.05$ was considered statistically significant. Data were analysed using SPSS V.16.0. ${ }^{48}$

\section{Patient and public involvement}

Parents were involved in the comprehensibility and feasibility testing of the surveys. The results of the study reflects parents and clinicians views which can be used to designing and interpreting the findings of intervention studies of probiotic therapy for prevention of AAD.

\section{RESULTS}

We approached 145 families and 125 clinicians of which 127 parents/guardians $(87.5 \%)$ and 45 paediatricians $(36 \%)$ responded. Lack of time or interest was the main reason of refusal among families, and respondents did not answer all questions (1\%-13\% missing values across different questions and participants). The mean age of children presenting to the emergency room on whose behalf their parents/guardians completed our survey was 6.5 years $(66 / 124,53 \%$ female). According to the parents/guardians, 39 out of 127 (31\%) of the children had previous experience of AAD. Most of the responding clinicians were general paediatricians $(17 / 39,44 \%)$ or paediatric emergency medicine sub-specialists $(15 / 39$, $38 \%$ ). Tables 1 and 2 show the general characteristics of responding parents/guardians and paediatricians, respectively.

\section{Parent/guardian and clinician knowledge and behaviour regarding probiotics \\ Parents/guardians}

One-hundred and twelve (88\%) of the 127 parents/ guardians were familiar with probiotics before doing the survey and 106/127 (84\%) had previously given their children probiotics, mostly as foods containing naturally occurring probiotics (eg, regular yoghourt, kefir, sauerkraut and kimchi) $(81 / 106 ; 76 \%)$ and foods containing supplemental probiotics (eg, yoghourts and drinks containing added probiotics) $(64 / 106 ; 60 \%)$. Thirty-two of 106 parents $(30 \%)$ had given their children probiotics in the form of supplements (eg, powder, capsule, chewable pill and drop/liquid). When asked which formulation their child would prefer (choose all that apply), most parents favoured drops/liquid form $(63 \%)$ of probiotic supplements. Chewable pills $(48 \%)$ and powder/sachet (42\%) were the next favourite options, followed by capsules (26\%); $3 \%$ selected none of the options.

\begin{tabular}{|c|c|}
\hline \multicolumn{2}{|l|}{ Child's age (years), $n=126$} \\
\hline Mean (SD) & $6.5(4.9)$ \\
\hline \multicolumn{2}{|l|}{ Child's gender, $n=124$} \\
\hline Female & $66(53 \%)$ \\
\hline \multicolumn{2}{|l|}{ Parent's age (years), $n=125$} \\
\hline 20 or less & $8(6 \%)$ \\
\hline $21-30$ & $20(16 \%)$ \\
\hline $31-40$ & $57(46 \%)$ \\
\hline $41-50$ & $31(25 \%)$ \\
\hline Over 50 & $9(7 \%)$ \\
\hline \multicolumn{2}{|l|}{ Parent's gender, $n=126$} \\
\hline Female & $98(77.8 \%)$ \\
\hline \multicolumn{2}{|l|}{ Parent's ethnicity, $n=123$} \\
\hline White/European/Caucasian & $80(65 \%)$ \\
\hline Asian (East, Southeast) & $15(12 \%)$ \\
\hline $\begin{array}{l}\text { Middle Eastern/South or West } \\
\text { Central Asian }\end{array}$ & $8(7 \%)$ \\
\hline Black & $6(5 \%)$ \\
\hline Latin American & $4(3 \%)$ \\
\hline North American Aboriginal & $5(4 \%)$ \\
\hline Other & $5(4 \%)$ \\
\hline \multicolumn{2}{|l|}{ Parent's education, $n=124$} \\
\hline Did not finish high school & $6(5 \%)$ \\
\hline High school diploma & $22(18 \%)$ \\
\hline $\begin{array}{l}\text { Post-secondary education without a } \\
\text { bachelor's degree }\end{array}$ & $39(31 \%)$ \\
\hline Bachelor's degree or higher & 57 (46\%) \\
\hline
\end{tabular}

Categorical variables are presented as $\mathrm{n}(\%)$.

\section{Clinicians}

Thirty-two of the 45 (71\%) paediatricians recommended probiotics for specific indications, 9/45 (20\%) selected 'other' (eg, 'If they want to take them I do not object', "I state that the current evidence for its use is limited and that there is a cost associated with their use. It could help and likely would not harm their child but could harm their pocket book."), 3/45 (7\%) did not know enough about probiotics to make any recommendations and 1/45 (2\%) did not recommend probiotics at all. Thirty-eight of the 45 paediatricians $(84 \%)$ stated that they recommended probiotics without parents asking them. Paediatricians mainly recommended probiotic supplements $(29 / 45,64 \%)$ or foods containing supplemental probiotics $(23 / 45,51 \%)$. The the most common indication for which they had recommended probiotics was prevention and treatment of AAD $(31 / 45,69 \%)$. Other indications were treatment $(23 / 45,51 \%)$ and prevention $(12 / 45,27 \%)$ of non-specific diarrhoea, prevention of necrotizing enterocolitis 
Table 2 Clinicians general characteristics

$\begin{array}{ll}\text { Gender, } \mathrm{n}=39 & \\ \text { Female } & 19(49 \%) \\ \text { Specialty, } \mathrm{n}=39 & 17(44 \%) \\ \quad \text { General paediatricians } & \\ \text { Sub specialists } & 15(38 \%) \\ \quad \text { Paediatric emergency medicine } & 5(13 \%) \\ \quad \text { Paediatric gastroenterology } & 2(5 \%) \\ \quad \text { Paediatric infectious disease } & \\ \text { Years since graduation, } \mathrm{n}=39 & 10.05(6.3) \\ \quad \text { Mean (SD) } & 10(5,15) \\ \quad \text { Median (Q1, Q3) } & \\ \text { Number of AAD patients in a typical month, } \\ \mathrm{n}=39\end{array}$

Categorical variables are presented as $\mathrm{n}(\%)$.

$(2 / 45,4 \%)$ and other conditions (10/45, 22\%) (eg, functional abdominal pain, functional constipation, inflammatory bowel disease, irritable bowel syndrome, infantile colic and cold).

Parent/guardian and clinician opinions regarding probiotics for prevention and treatment of AAD

Compared with parents, paediatricians more frequently agreed or strongly agreed that probiotics were effective ( 77 vs $48 \%, \mathrm{p}=0.001$ ) and safe (98 vs $62 \%, \mathrm{p}<0.001$ ) for prevention of AAD. Three (2\%) parents and none of the clinicians disagreed or strongly disagreed that probiotics were safe for prevention of AAD (table 3).

\section{Minimally important difference}

Sixty-four out of 125 responding parents $(51 \%)$ and 21 out of 41 responding clinicians $(51 \%)$ reported they would use probiotics if it could reduce the RR of AAD by $39 \%$ (ie, reduce the absolute risk of AAD from $19 \%$ to $12 \%$; yielding a number needed to treat of 13 and a RR of 0.61) (table 4). Paediatricians were most likely to choose a RR reduction of $54 \%$ or less than compared with parents ( 85 vs $65 \%$; $\mathrm{OR}=3,95 \%$ CI 1.14 to $9.54, \mathrm{p}=0.02$ )

There was no association between parental age, gender, ethnicity, education, previous familiarity with probiotics, previous use of probiotics, child's previous experience of $\mathrm{AAD}$ and parental opinion about the safety of probiotics with the choice of MID ( $>0.05)$ (online supplementary appendix $\mathrm{C})$. In addition, there was no association between clinician's gender, specialty, years since graduation, the number of AAD patients seen per month, previous familiarity and recommendation of probiotics and clinician's opinion about the safety of probiotics with the choice of MID ( $>>0.05$ ) (online supplementary appendix $\mathrm{C}$ ).

\section{Important outcomes}

According to GRADE, ${ }^{46}$ outcomes should be measured in clinical trials if more than $70 \%$ of respondents rate them between 7 and 9 (critical) and less than $15 \%$ rate them between 1 and 3 (limited importance) on a scale of 1-9.

In our study, the most important outcomes to parents in descending order were - need for hospitalisation, prevention of dehydration, disruption of normal daily activities,

Table 3 Parent/guardian and clinician opinions about effectiveness and safety of probiotics for prevention and treatment of antibiotic-associated diarrhoea

\begin{tabular}{|c|c|c|c|c|c|c|c|c|c|}
\hline & & & $\begin{array}{l}\text { Strongly } \\
\text { agreed }\end{array}$ & Agreed & Neutral & Disagreed & $\begin{array}{l}\text { Strongly } \\
\text { disagreed }\end{array}$ & $\begin{array}{l}\text { Do not } \\
\text { know }\end{array}$ & $P$ value \\
\hline \multirow[t]{4}{*}{ Prevention } & Effective & $\begin{array}{l}\text { Parents } \\
n=126\end{array}$ & 19 (15\%) & 41 (33\%) & $22(17 \%)$ & $5(4 \%)$ & $6(5 \%)$ & 33 (26\%) & 0.001 \\
\hline & & $\begin{array}{l}\text { Clinicians } \\
n=44\end{array}$ & $10(23 \%)$ & 24 (54\%) & $6(14 \%)$ & $4(9 \%)$ & 0 & 0 & \\
\hline & Safe & $\begin{array}{l}\text { Parents } \\
n=123\end{array}$ & 38 (31\%) & 38 (31\%) & $26(21 \%)$ & 0 & $3(2 \%)$ & $18(15 \%)$ & 0.000 \\
\hline & & $\begin{array}{l}\text { Clinicians } \\
\mathrm{n}=44\end{array}$ & 17 (39\%) & 26 (59\%) & $1(2 \%)$ & 0 & 0 & 0 & \\
\hline \multirow[t]{4}{*}{ Treatment } & Effective & $\begin{array}{l}\text { Parents } \\
n=126\end{array}$ & 17 (14\%) & 37 (29\%) & $23(18 \%)$ & $3(2 \%)$ & $6(5 \%)$ & 40 (32\%) & 0.000 \\
\hline & & $\begin{array}{l}\text { Clinicians } \\
n=43\end{array}$ & $6(14 \%)$ & 23 (53\%) & $11(26 \%)$ & $3(7 \%)$ & 0 & 0 & \\
\hline & Safe & $\begin{array}{l}\text { Parents } \\
n=123\end{array}$ & 34 (28\%) & 39 (32\%) & $21(17 \%)$ & $1(1 \%)$ & $4(3 \%)$ & 24 (19\%) & 0.000 \\
\hline & & $\begin{array}{l}\text { Clinicians } \\
\mathrm{n}=43\end{array}$ & $13(30 \%)$ & 28 (65\%) & $2(5 \%)$ & 0 & 0 & 0 & \\
\hline
\end{tabular}

Data are presented as $\mathrm{n}(\%)$.

$A A D$, antibiotic-associated diarrhoea; NS, non-significant. 
Table 4 Parent/guardian and clinician opinions about minimally important difference

\begin{tabular}{lll}
\hline $\begin{array}{l}\text { MID options - Absolute risk of } \\
\text { diarrhoea in probiotic group, } \\
\text { assuming 19\% in control group }\end{array}$ & $\begin{array}{l}\text { Parents } \\
(\mathbf{n}=125)\end{array}$ & $\begin{array}{l}\text { Clinicians } \\
(\mathbf{n}=\mathbf{4 1 )}\end{array}$ \\
\hline $12 \%(\mathrm{NNT}=13, \mathrm{RRR}=0.39)$ & $64(51 \%)$ & $21(51 \%)$ \\
\hline $9 \%(\mathrm{NNT}=10, \mathrm{RRR}=0.54)$ & $18(14 \%)$ & $14(34 \%)$ \\
$7 \%(\mathrm{NNT}=8, \mathrm{RRR}=0.65)$ & $33(27 \%)$ & $6(15 \%)$ \\
$\begin{array}{l}\text { I would not give (recommend) } \\
\text { probiotics for AAD prevention }\end{array}$ & $10(8 \%)$ & 0 \\
\hline
\end{tabular}

MID, minimally important difference; NNT, number needed to treat; $\mathrm{RRR}$, relative risk reduction.

diarrhoea duration and physician revisit (table 5). Paediatricians considered the need for hospitalisation along with physician revisit as the most important outcomes. Moreover, they also rated prevention of dehydration, diarrhoea duration and stool frequency as critical outcomes to be measured in clinical trials (table 5).

\section{DISCUSSION}

Our study showed that half of the parents of children presenting to the emergency department of a Canadian tertiary care children's hospital and half of the paediatricians working in that hospital required at least a 39\% reduction in the RR of paediatric antibiotic-associated diarrhoea (ie, decrease the absolute AAD risk from 19\% to $12 \%$ ) to consider it worthwhile to consume/recommend probiotics. No associated factors (eg, demographic characteristics, previous experience of AAD and familiarity with probiotics) were found to be related with the choice of MID in either group.

There are multiple approaches to establish MID in the current literature: anchor-based, distribution-based, health economic, pilot studies, review of the existing evidence and opinion-seeking. ${ }^{16}$ However, most of them are not considered patient-centred approaches. Although anchor-based methods reflect patients' views about the amount of experienced change, most often researchers decide on the threshold scores for MID. In addition, this method usually relies on change of symptoms over time rather than differences between patients with and without intervention. ${ }^{19}$

To obtain parent preferences about MID, we used the benefit-harm trade off tool providing advantages and disadvantages (eg, side effects, costs and inconvenience) of the intervention. This method has been used in various studies in other settings. ${ }^{4-54}$ In addition to considering

Table 5 Parent/guardian and clinician opinions regarding importance of outcomes in clinical trials of antibiotic-associated diarrhoea

\begin{tabular}{|c|c|c|c|c|c|}
\hline Outcomes & & $\begin{array}{l}\text { Limited } \\
\text { importance }\end{array}$ & Important but not critical & Critical & P value* \\
\hline \multirow[t]{2}{*}{ Stool frequency } & Parents $(n=125)$ & 17 (14\%) & $50(40 \%)$ & $58(46 \%)$ & 0.002 \\
\hline & Clinicians $(n=40)$ & $1(2 \%)$ & $8(20 \%)$ & $31(78 \%)$ & \\
\hline \multirow[t]{2}{*}{ Stool consistency } & Parents $(n=125)$ & $6(5 \%)$ & $38(30 \%)$ & $81(65 \%)$ & 0.03 \\
\hline & Clinicians $(n=40)$ & $2(5 \%)$ & 21 (53\%) & $17(42 \%)$ & \\
\hline \multirow{2}{*}{$\begin{array}{l}\text { Duration of } \\
\text { diarrhoea }\end{array}$} & Parents $(n=125)$ & $3(2 \%)$ & $26(21 \%)$ & $96(77 \%)$ & NS \\
\hline & Clinicians $(n=40)$ & $1(2 \%)$ & $7(18 \%)$ & $32(80 \%)$ & \\
\hline \multirow[t]{2}{*}{ Dehydration } & Parents $(n=125)$ & $3(2 \%)$ & $15(12 \%)$ & $108(86 \%)$ & NS \\
\hline & Clinicians $(n=40)$ & $1(2 \%)$ & $7(18 \%)$ & $32(80 \%)$ & \\
\hline \multirow{2}{*}{$\begin{array}{l}\text { Effect on normal } \\
\text { daily activities (eg, } \\
\text { eating, sleeping and } \\
\text { playing) }\end{array}$} & Parents $(n=125)$ & 0 & 19 (15\%) & $106(85 \%)$ & 0.004 \\
\hline & Clinicians $(n=40)$ & $1(2 \%)$ & $14(35 \%)$ & $25(63 \%)$ & \\
\hline \multirow{2}{*}{$\begin{array}{l}\text { Child absence from } \\
\text { daycare or school }\end{array}$} & Parents $(n=125)$ & $19(15 \%)$ & $31(25 \%)$ & $75(60 \%)$ & NS \\
\hline & Clinicians $(n=40)$ & $3(7 \%)$ & $16(40 \%)$ & $21(53 \%)$ & \\
\hline \multirow{2}{*}{$\begin{array}{l}\text { Parental absence } \\
\text { from work }\end{array}$} & Parents $(n=125)$ & $30(24 \%)$ & $31(25 \%)$ & $64(51 \%)$ & NS \\
\hline & Clinicians $(n=40)$ & $4(10 \%)$ & $14(36 \%)$ & $21(54 \%)$ & \\
\hline \multirow{2}{*}{$\begin{array}{l}\text { Need for } \\
\text { hospitalisation }\end{array}$} & Parents $(n=125)$ & $3(2 \%)$ & $8(7 \%)$ & $113(91 \%)$ & NS \\
\hline & Clinicians $(n=40)$ & $1(2 \%)$ & $4(10 \%)$ & $35(88 \%)$ & \\
\hline \multirow{2}{*}{$\begin{array}{l}\text { Need for outpatient } \\
\text { or emergency } \\
\text { department visit }\end{array}$} & Parents $(n=125)$ & $7(6 \%)$ & $23(18 \%)$ & 95 (76\%) & NS \\
\hline & Clinicians $(n=40)$ & $1(2 \%)$ & $4(10 \%)$ & 35 (88\%) & \\
\hline
\end{tabular}

${ }^{\star}$ For the comparison between parents and clinicians.

NS, non-significant. 
the patient's perspective, this method is specific to the intervention and is based on between-group comparisons. ${ }^{1819}$

In the majority of the previous studies comparing patient and healthcare provider opinions, patients wanted larger effect sizes before opting for an intervention than did healthcare providers. ${ }^{55-60}$ In our study, although clinicians were more convinced than were parents that probiotics are safe and effective, the MIDs were relatively similar. Only $8 \%$ of parents and none of the clinicians were unwilling to use probiotics for AAD. The high rates of familiarity and use of probiotics, limited costs and inconvenience and the favourable safety profile of probiotics may explain this preference.

The level of familiarity (88\%) and use of probiotics $(84 \%)$ by parents/guardians were high in our study compared with others. Chin-Lee et al in $2014,{ }^{61}$ reported that $65 \%$ of their respondents were familiar with the term 'probiotics' and only $30 \%$ had used them before. Another study in New Zealand $(2011)^{62}$ also showed a low rate $(25 \%)$ of probiotic use. Studies in the Netherlands in $2013(50 \%),{ }^{63}$ Brazil in $2008(29 \%)^{64}$ and Greece in 2005 $(18 \%-29 \%)^{65}$ reported even less familiarity with the term and meaning of probiotics. It is possible that the general population has greater awareness about the potential health benefits of probiotic products over time, but it also seems parents in Canada have a more positive attitude towards probiotics than do those in other countries.

In 2014, a core outcome set was developed for clinical trials of acute diarrhoea in children. ${ }^{66}$ Outcomes included prevention of hospitalisation, diarrhoea and dehydration, similar to the outcomes of greatest importance to our participants. Employing outcomes that reflect patient/ parent and clinician opinions will increase the acceptability and relevance of these studies.

\section{Strengths and limitations}

Our study is the first to seek parent and clinician opinions about MID of probiotic therapy for preventing paediatric AAD. Before recruitment, a pilot and clinical sensibility testing were conducted to ensure the comprehensibility and feasibility of the surveys, and revisions were made based on the results. Response rate of parents/guardians was very high since the survey was conducted in the emergency department waiting room with in-person support.

Our study has some limitations. It was restricted to individuals who could communicate in English. In addition, we only recruited parents of children presenting to a children's hospital emergency department, which represent a small fraction of children who are prescribed antibiotics. These might affect the generalisability of our findings. The level of education in our participating parents was higher than the level of education in people living in Alberta (Canada). ${ }^{67}$ Although, education level and previous familiarity with probiotics were not correlated with the choice of MID in our study, these characteristics might affect the generalisability of our findings. In addition, all our participating clinicians were paediatricians who may be more familiar with probiotics than other medical specialists. Similar to previous studies, ${ }^{68}$ there was a low response rate from clinicians despite sending two reminders after the first invitation. According to VanGeest $e t a l,{ }^{69}$ the most common reasons for non-responders are being busy and considering surveys as a low priority task compared with their other duties. Moreover, in our study, the administration method was different for parents/guardians (in-person) and clinicians (online) which might have an effect on their response rate.

\section{Implication}

Findings of our study regarding MID will inform future RCTs to calculate sample size and interpret findings informed by parental and clinician perspectives. Given that parents/caregivers are the ultimate decision-makers about their child's health, especially for treatments that are easily available without a prescription, employing the outcomes that are most important to them will also improve the applicability and relevance of future studies.

\section{CONCLUSION}

There is a good agreement between parents and clinicians regarding how effective probiotics need to be in preventing $\mathrm{AAD}$ in order to warrant use. This information, along with the outcomes they perceived important, will help designing future clinical trials.

Acknowledgements We would like to thank all our participants who generously provided their time and participated in our survey study.

Contributors SKA developed the methods, designed the electronic and paper surveys, gained ethical approval for the study, recruited participants, performed statistical analysis, drafted the initial manuscript and revised the manuscript. JR, $\mathrm{LAD}, \mathrm{HQH}$ and $\mathrm{HJ}$ participated in developing the methods of the study, participated in the interpretation of data and critically reviewed and edited the manuscript. SV guided the development and conduct of the study, participated in the interpretation of data and critically reviewed and edited the manuscript. All authors approved the final manuscript as submitted and agreed to be accountable for all aspects of the work.

Funding This research was funded by the generous support of the Stollery Children's Hospital Foundation through the Women and Children's Health Research Institute.

\section{Competing interests None declared.}

Patient consent for publication Not required.

Ethics approval The Health Research Ethics Board of University of Alberta, Canada approved this study.

Provenance and peer review Not commissioned; externally peer reviewed.

Data sharing statement Parents and clinicians surveys are available as online supplementary information.

Open access This is an open access article distributed in accordance with the Creative Commons Attribution Non Commercial (CC BY-NC 4.0) license, which permits others to distribute, remix, adapt, build upon this work non-commercially, and license their derivative works on different terms, provided the original work is properly cited, appropriate credit is given, any changes made indicated, and the use is non-commercial. See: http://creativecommons.org/licenses/by-nc/4.0/.

\section{REFERENCES}

1. FAO/WHO. Joint working group guidelines for probiotics in food: WHO, 2002. 
2. Hill C, Guarner F, Reid G, et al. Expert consensus document. The International Scientific Association for Probiotics and Prebiotics consensus statement on the scope and appropriate use of the term probiotic. Nat Rev Gastroenterol Hepatol 2014;11:506-14

3. Zorzela L, Ardestani SK, McFarland LV, et al. Is there a role for modified probiotics as beneficial microbes: a systematic review of the literature. Benef Microbes 2017:8:739-54.

4. Goldenberg JZ, Lytvyn L, Steurich J, et al. Probiotics for the prevention of pediatric antibiotic-associated diarrhea. Cochrane Database Syst Rev 2015;12:CD004827.

5. Bartlett JG. Antibiotic-associated diarrhea. N Engl J Med Overseas Ed 2002;346:334-9.

6. La Rosa M, Bottaro G, Gulino N, et al. [Prevention of antibioticassociated diarrhea with Lactobacillus sporogens and fructooligosaccharides in children. A multicentric double-blind vs placebo study]. Minerva Pediatr 2003;55:447-52.

7. McFarland LV. Epidemiology, risk factors and treatments for antibiotic-associated diarrhea. Dig Dis 1998;16:292-307.

8. Wiström J, Norrby SR, Myhre EB, et al. Frequency of antibioticassociated diarrhoea in 2462 antibiotic-treated hospitalized patients: a prospective study. J Antimicrob Chemother 2001;47:43-50.

9. Beaugerie L, Petit JC. Microbial-gut interactions in health and disease. Antibiotic-associated diarrhoea. Best Pract Res Clin Gastroenterol 2004;18:337-52.

10. Bergogne-Bérézin $E$. Treatment and prevention of antibiotic associated diarrhea. Int J Antimicrob Agents 2000;16:521-6.

11. Berrington A, Borriello SP, Brazier J, et al. National Clostridium difficile Standards Group. National Clostridium difficile Standards Group: Report to the Department of Health. J Hosp Infect 2004;56(Suppl1):1-38.

12. McFarland LV, Goh S. Preventing pediatric antibiotic-associated diarrhea and Clostridium difficile infections with probiotics: A metaanalysis. World J Meta-Anal 2013:1:02-120.

13. Varughese CA, Vakil NH, Phillips KM. Antibiotic-associated diarrhea: a refresher on causes and possible prevention with probiotics-continuing education article. J Pharm Pract 2013;26:476-82.

14. Rossignoli A, Clavenna A, Bonati M. Antibiotic prescription and prevalence rate in the outpatient paediatric population: analysis of surveys published during 2000-2005. Eur J Clin Pharmacol 2007;63:1099-106.

15. Schulz KF, Altman DG, Moher D. CONSORT Group. CONSORT 2010 statement: updated guidelines for reporting parallel group randomized trials. Ann Intern Med 2010;152:726-32.

16. Cook JA, Hislop J, Adewuyi TE, et al. Assessing methods to specify the target difference for a randomised controlled trial: DELTA (Difference ELicitation in TriAls) review. Health Technol Assess 2014;18:v-vi, 1-175.

17. Jaeschke R, Singer J, Guyatt GH. Measurement of health status. Ascertaining the minimal clinically important difference. Control Clin Trials 1989;10:407-15.

18. Ferreira ML, Herbert RD, Crowther MJ, et al. When is a further clinical trial justified? BMJ 2012;345:e5913.

19. Ferreira ML, Herbert RD, Ferreira PH, et al. A critical review of methods used to determine the smallest worthwhile effect of interventions for low back pain. J Clin Epidemiol 2012;65:253-61.

20. Arvola T, Laiho K, Torkkeli S, et al. Prophylactic Lactobacillus GG reduces antibiotic-associated diarrhea in children with respiratory infections: a randomized study. Pediatrics 1999;104:e64.

21. Benhamou PH, Berlier P, Danjou G, et al. Antibiotic-associated diarrhoea in children: a computer monitored double-blind outpatients trial comparing a protective and a probiotic agent. Méd Chir Dig 1999;28:163-8

22. Contardi I. Oral bacterial therapy in prevention of antibiotic-induced diarrhea in childhood [Batterioterapia orale quale prevenzione della diarrea da antibiotici in eta pediatrica]. Clinica Terapeutica 1991;136:409-13.

23. Conway $S$, Hart $A$, Clark $A$, et al. Does eating yogurt prevent antibiotic-associated diarrhoea? A placebo-controlled randomised controlled trial in general practice. Br J Gen Pract 2007;57:953-9.

24. Corrêa NB, Péret Filho LA, Penna FJ, et al. A randomized formula controlled trial of Bifidobacterium lactis and Streptococcus thermophilus for prevention of antibiotic-associated diarrhea in infants. J Clin Gastroenterol 2005;39:385-9.

25. Erdeve O, Tiras $U$, Dallar $Y$. The probiotic effect of Saccharomyces boulardii in a pediatric age group. J Trop Pediatr 2004;50:234-8.

26. Fox MJ, Ahuja KD, Robertson IK, et al. Can probiotic yogurt prevent diarrhoea in children on antibiotics? A double-blind, randomised, placebo-controlled study. BMJ Open 2015;5:e006474.

27. Jirapinyo P, Densupsoontorn N, Thamonsiri N, et al. Prevention of antibiotic-associated diarrhea in infants by probiotics. J Med Assoc Thai 2002;85(Suppl2):s739-42.
28. Ahmad K, Fatemeh F, Mehri N, et al. Probiotics for the treatment of pediatric helicobacter pylori infection: a randomized double blind clinical trial. Iran J Pediatr 2013;23:79-84.

29. Kotowska M, Albrecht P, Szajewska H. Saccharomyces boulardii in the prevention of antibiotic-associated diarrhoea in children: a randomized double-blind placebo-controlled trial. Aliment Pharmacol Ther 2005;21:583-90.

30. Merenstein DJ, Foster J, D'Amico F. A randomized clinical trial measuring the influence of kefir on antibiotic-associated diarrhea: the measuring the influence of Kefir (MILK) Study. Arch Pediatr Adolesc Med 2009;163:750-4.

31. Ruszczyński M, Radzikowski A, Szajewska H. Clinical trial: effectiveness of Lactobacillus rhamnosus (strains E/N, Oxy and Pen) in the prevention of antibiotic-associated diarrhoea in children. Aliment Pharmacol Ther 2008:28:154-61.

32. Saneeyan H, Layegh S, Rahimi H. Effectivness of probiotic on treatment of Helicobacter pylori infection in children. I.u.m.s 2011;29:882-9.

33. Shan LS, Hou P, Wang ZJ, et al. Prevention and treatment of diarrhoea with Saccharomyces boulardii in children with acute lower respiratory tract infections. Benef Microbes 2013;4:329-34.

34. Sýkora J, Valecková K, Amlerová J, et al. Effects of a specially designed fermented milk product containing probiotic Lactobacillus casei DN-114 001 and the eradication of $\mathrm{H}$. pylori in children: a prospective randomized double-blind study. J Clin Gastroenterol 2005;39:692-8.

35. Szajewska H, Albrecht P, Topczewska-Cabanek A. Randomized, double-blind, placebo-controlled trial: effect of lactobacillus GG supplementation on Helicobacter pylori eradication rates and side effects during treatment in children. J Pediatr Gastroenterol Nutr 2009;48:431-6.

36. Szymański H, Armańska M, Kowalska-Duplaga K, et al. Bifidobacterium longum PL03, Lactobacillus rhamnosus KL53A, and Lactobacillus plantarum PL02 in the prevention of antibioticassociated diarrhea in children: a randomized controlled pilot trial. Digestion 2008;78:13-17.

37. Tankanow RM, Ross MB, Ertel IJ, et al. A double-blind, placebocontrolled study of the efficacy of Lactinex in the prophylaxis of amoxicillin-induced diarrhea. DICP 1990;24:382-4.

38. Vanderhoof JA, Whitney DB, Antonson DL, et al. Lactobacillus GG in the prevention of antibiotic-associated diarrhea in children. $J$ Pediatr 1999;135:564-8

39. Zheng YJ, Mao ZQ. Investigating Group for Prevention of AAD in Children with Pneumonia by Clostridium Butyricum and Bifidobacterium. [Multicenter, randomized, controlled clinical trial on preventing antibiotic-associated diarrhea in children with pneumonia using the live Clostridium butyricum and Bifidobacterium combined Powder]. Zhonghua Er Ke Za Zhi 2012;50:732-6.

40. Schünemann HJ, Guyatt GH, Commentary-goodbye M. C) ID! Hello MID. where do you come from? Health serv res 2005;40:593-7.

41. Harris PA, Taylor R, Thielke R, et al. Research electronic data capture (REDCap)--a metadata-driven methodology and workflow process for providing translational research informatics support. J Biomed Inform 2009;42:377-81.

42. Kligler B, Hanaway P, Cohrssen A. Probiotics in children. Pediatr Clin North Am 2007;54:949-67. xi.

43. Gigerenzer G, Edwards A. Simple tools for understanding risks: from innumeracy to insight. BMJ 2003;327:741-4.

44. Edwards A, Elwyn G, Mulley A. Explaining risks: turning numerical data into meaningful pictures. BMJ 2002;324:827-30.

45. Li KK, Holbrook AM, Thabane L, et al. A survey of physicians show a one-third reduction in harmful outcomes to be a clinically important difference for statin therapy. J Clin Epidemiol 2012;65:954-61.

46. Guyatt GH, Oxman AD, Kunz R, et al. GRADE guidelines: 2. Framing the question and deciding on important outcomes. J Clin Epidemiol 2011;64:395-400.

47. Cohen J. Statistical Power Analysis for the Behavioral Sciences. Hillsdale, New Jersey: Lawrence Erlbaum Associates, 1988.

48. SPSS Inc. Released 2007. SPSS for Windows, Version 16.0. Chicago: SPSS Inc.

49. Barrett B, Brown R, Mundt M, et al. Using benefit harm tradeoffs to estimate sufficiently important difference: the case of the common cold. Med Decis Making 2005;25:47-55.

50. Barrett B, Harahan B, Brown D, et al. Sufficiently important difference for common cold: severity reduction. Ann Fam Med 2007;5:216-23.

51. Duric VM, Butow PN, Sharpe L, et al. Comparing patients' and their partners' preferences for adjuvant chemotherapy in early breast cancer. Patient Educ Couns 2008;72:239-45.

52. Duric V, Stockler M, Heritier S, et al. Patients' preferences for adjuvant chemotherapy in early breast cancer: what makes $A C$ and CMF worthwhile now? Ann Oncol 1786;2005:e94. 
53. Hirose $\mathrm{T}$, Horichi N, Ohmori T, et al. Patients preferences in chemotherapy for advanced non-small cell lung cancer. Intern Med 2005;44:107:e13.

54. Petherick ES, O'Meara S, Spilsbury K, et al. Patient acceptability of larval therapy for leg ulcer treatment: a randomised survey to inform the sample size calculation of a randomised trial. BMC Med Res Methodol 2006;6:43e6.

55. McAlister FA, O'Connor AM, Wells G, et al. When should hypertension be treated? The different perspectives of Canadian family physicians and patients. CMAJ 2000;163:403-8.

56. Aarabi M, Skinner J, Price CE, et al. Patients' acceptance of antihypertensive therapy to prevent cardiovascular disease: a comparison between South Asians and Caucasians in the United Kingdom. Eur J Cardiovasc Prev Rehabil 2008;15:59-66.

57. Lewis DK, Barton S. Who decides when to start preventive treatment? A questionnaire survey to compare the views of different population subgroups. J Epidemiol Community Health 2003;57:241-2.

58. Steel N. Thresholds for taking antihypertensive drugs in different professional and lay groups: questionnaire survey. BMJ 2000;320:1446-7.

59. Murphy DJ, Gahm GJ, Santilli S, et al. Seniors' preferences for cancer screening and medication use based on absolute risk reduction. J Gerontol A Biol Sci Med Sci 2002;57:M100-5.

60. Hudson B, Zarifeh A, Young L, et al. Patients' expectations of screening and preventive treatments. Ann Fam Med 2012;10:495-502.
61. Chin-Lee B, Curry WJ, Fetterman J, et al. Patient experience and use of probiotics in community-based health care settings. Patient Prefer Adherence 2014;8:1513.

62. Schultz M, Baranchi A, Thurston L, et al. Consumer demographics and expectations of probiotic therapy in New Zealand: results of a large telephone survey. N Z Med J 2011;124:36-43.

63. Rijkers GT, Bimmel D, Grevers D, et al. Consumer perception of beneficial effects of probiotics for human health. Benef Microbes 2013;4:117-21.

64. Viana JV, da Cruz AG, Zoellner SS, et al. Probiotic foods: consumer perception and attitudes. Int J Food Sci Technol 2008;43:1577-80.

65. Babajimopoulos M. Consumer's knowledge on probiotics and consumption of these products in the city of Thessaloniki, Greece. Consumer \& Nutrition 2005:155.

66. Karas J, Ashkenazi S, Guarino A, et al. Consensus Group on Outcome Measures Made in Paediatric Enteral Nutrition Clinical Trials (COMMENT). A core outcome set for clinical trials in acute diarrhoea. Arch Dis Child 2015;100:359-63.

67. Statistics Canada. Education Highlight Tables. Census. 2016 https:// www12.statcan.gc.ca/census-recensement/2016/dp-pd/hlt-fst/ edu-sco/Table.cfm? Lang=E\&T=11\&Geo=00\&SP=1\&view=2\&age=1\& sex $=1$ (Accessed 6 Nov 2018).

68. Cho YI, Johnson TP, Vangeest JB. Enhancing surveys of health care professionals: a meta-analysis of techniques to improve response. Eval Health Prof 2013;36:382-407.

69. VanGeest JB, Johnson TP, Welch VL. Methodologies for improving response rates in surveys of physicians: a systematic review. Eval Health Prof 2007;30:303-21. 